\title{
Diagnostic evaluation and medication usage in a cohort of subjects with juvenile dermatomyositis from the CARRAnet registry
}

\author{
Angela B Robinson ${ }^{5 *}$, Mark F Hoeltzel ${ }^{2}$, Ann M Reed ${ }^{4}$, Adam Huber $^{3}$, Brian M Feldman ${ }^{6}$, \\ Juvenile Myositis CARRA Subgroup
}

From 2011 Pediatric Rheumatology Symposium sponsored by the American College of Rheumatology Miami, FL, USA. 2-5 June 2011

\section{Purpose}

Juvenile dermatomyositis (JDM) is a rare disease which has been difficult to evaluate objectively due to the low incidence of disease. The Childhood Arthritis and Rheumatology Research Alliance (CARRA) initiated a multicenter observational registry to create a clinical database for the major rheumatic diseases of childhood, including JDM. Initial data from the JDM cohort (prevalent and incident cases) enrolled in the first 7 months of this ongoing study are evaluated here.

\section{Methods}

Children under 21 yrs with onset of JDM prior to $16 \mathrm{yrs}$ were included, and subjects or their guardians were consented for the study. IRB approval was obtained at each enrolling site. JDM was diagnosed by modified Bohan and Peter criteria. Clinical data were collected from the subjects, guardians, and providers using both general and JDM-specific case report forms at the time of enrollment. Data regarding demographics, diagnostic assessment, and medication exposure were collected. Data were pooled and stored in a secure centralized database and de-identified prior to analysis.

\section{Results}

Between May 28, 2010 and December 28, 2010, 102 subjects meeting modified criteria for JDM were enrolled from 23 sites in the U.S. Diagnostic studies commonly used include electromyography (EMG), muscle biopsy, and magnetic resonance imaging (MRI). Overall, MRI was more likely than EMG or muscle biopsy to show

${ }^{5}$ Rainbow Babies and Childrens Hospital, Cleveland, OH, USA

Full list of author information is available at the end of the article abnormalities. (Table 1) 48 of subjects had 2 or more studies performed and $54.2 \%$ of these subjects reported at least 1 negative study. In terms of medications, 100\% of subjects have been exposed to corticosteroids during their course of treatment, and $97 \%$ of subjects have been exposed to methotrexate, suggesting that these medications are almost universally prescribed for JDM. Medication history in order of frequency of usage is shown in Table 2.

\section{Conclusion}

MRI was the most common diagnostic modality used and was the most likely to show abnormalities consistent with JDM. The false negative rates for MRI, EMG, and muscle biopsy alone were higher than expected if ascertainment is correct. Corticosteroids and methotrexate appear to be

Table 1 Evaluation of diagnostic modalities in JDM

\begin{tabular}{ll}
\hline & $N(\%)$ \\
\hline Muscle biopsy $(\mathrm{n}=89)$ & $44(49.4)$ \\
Performed & $29(65.9)$ \\
Consistent with JDM & \\
EMG $(\mathrm{n}=86)$ & $36(41.9)$ \\
Performed & $25(69.4)$ \\
Consistent with JDM & \\
MRI ( $\mathrm{n}=87)$ & $74(85.1)$ \\
Performed & $61(82.4)$ \\
Consistent with JDM & \\
Combination of $\geq 2$ studies ( $\mathrm{n}=91)$ & $48(52.7)$ \\
Performed & $26(54.2)$ \\
2 studies consistent with JDM & $22(45.8)$ \\
A study consistent with JDM &
\end{tabular}


Table 2 Medication usage with the CARRAnet JDM cohort $(\mathrm{N}=102)$

\begin{tabular}{lllll}
\hline & $\begin{array}{l}\text { Current } \\
\text { use }\end{array}$ & $\begin{array}{l}\text { Previous } \\
\text { use }\end{array}$ & $\begin{array}{l}\text { Never } \\
\text { used }\end{array}$ & Missing \\
\hline All corticosteroids & $51(52.6 \%)$ & $46(47.4 \%)$ & $0(0.0 \%)$ & 5 \\
Daily corticosteroids & $50(51.5 \%)$ & $46(47.4 \%)$ & $1(1.1 \%)$ & 5 \\
Methotrexate & $65(68.4 \%)$ & $27(28.4 \%)$ & $3(3.2 \%)$ & 7 \\
Pulse corticosteroids & $4(4.2 \%)$ & $48(50.5 \%)$ & $43(45.3 \%)$ & 7 \\
Hydroxychlorquine & $39(41.1 \%)$ & $17(17.9 \%)$ & $39(41.1 \%)$ & 7 \\
Intravenous & $24(24.5 \%)$ & $24(24.5 \%)$ & $50(51.0 \%)$ & 4 \\
gammaglobulin & $13(13.7 \%)$ & $5(5.3 \%)$ & $77(81.1 \%)$ & 7 \\
Mycophenolate mofetil & $4(4.2 \%)$ & $5(5.3 \%)$ & $86(90.5 \%)$ & 7 \\
Cyclosporine A & $1(1.0 \%)$ & $7(7.1 \%)$ & $90(91.8 \%)$ & 4 \\
Rituximab & $0(0.0 \%)$ & $2(2.1 \%)$ & $93(97.9 \%)$ & 7 \\
Cyclophosphamide & & & & \\
\hline
\end{tabular}

standard first line medications used by US pediatric rheumatologists for JDM. Pulse corticosteroids, intravenous gammaglobulin, and hydroxychloroquine have been used by about half of subjects and further investigation as to which subgroups receive these medications is warranted.

\section{Disclosure}

Angela B. Robinson: None; Mark F. Hoeltzel: None; Ann M. Reed: None; Adam Huber: None; Brian M. Feldman: Baxter, 2, Bayer, 2, Novartis Pharmaceuticals Corporation, 6; Juvenile Myositis CARRA Subgroup: None.

\section{Author details}

${ }^{1}$ CARRAnet Investigators. ${ }^{2}$ Children's Mercy Hospital, Kansas City, MO, USA. ${ }^{3}$ IWK Health Centre, Halifax, NS, Canada. ${ }^{4}$ Mayo Clinic, Rochester, MN, USA. ${ }^{5}$ Rainbow Babies and Childrens Hospital, Cleveland, OH, USA. ${ }^{6}$ The Hospital for Sick Children, Toronto, ON, Canada.

Published: 13 July 2012

\section{doi:10.1186/1546-0096-10-S1-A64}

Cite this article as: Robinson et al:: Diagnostic evaluation and

medication usage in a cohort of subjects with juvenile dermatomyositis

from the CARRAnet registry. Pediatric Rheumatology 2012 10(Suppl 1):A64.
Submit your next manuscript to BioMed Central and take full advantage of:

- Convenient online submission

- Thorough peer review

- No space constraints or color figure charges

- Immediate publication on acceptance

- Inclusion in PubMed, CAS, Scopus and Google Scholar

- Research which is freely available for redistribution

Submit your manuscript at www.biomedcentral.com/submit 